\title{
载人深潜技术的发展与应用
}

\author{
胡震，曹俊 \\ (中国船舶科学研究中心, 江苏无锡, 214082)
}

\begin{abstract}
摘要：载人潜水器是深海进入、探测、开发和保护的重要技术手段和装备, 代表着潜水器技术的发展前沿。本文简述了国外 深海载人潜水器装备与技术的发展现状, 梳理了我国在本领域的装备与技术发展以及探索应用情况, 重点介绍了我国载人深 潜技术三大里程碑成就: 基于 “蛟龙” 号和 “深海勇士” 号的研制经验, 形成了我国载人深潜技术体系; 在 4500 7000 m 潜 深范围, 我国载人深潜技术总体上已处于国际前沿, 且具有自主知识产权; 载人深潜技术向着全海深、全海域的谱系化发展 思路已趋于明朗。未来 15 年, 我国载人潜水器领域的发展重点是巩固提高作业能力, 积极拓展应用领域, 不断提高智能化、 轻量化、重载化和集群协同水平, 精心打造产业链条, 成为载人深潜技术强国。
\end{abstract}

关键词: 潜水器; 载人; 深海; 关键技术; 谱系化

中图分类号：TP 242 文献标识码：A

\section{Development and Application of Manned Deep Diving Technology}

\author{
Hu Zhen, Cao Jun
}

(China Ship Scientific Research Center, Wuxi 214082, Jiangsu, China)

\begin{abstract}
Manned submersible is an important technical means and equipment for deep sea entry, exploration, development, and protection, which represents the development frontier of the submersible technology. In this paper, the development status of the equipment and technology of deep-sea manned submersibles abroad is briefly described, and the development and application of the same in China are then reviewed. The three milestones for the development of deep-sea manned submersible technology in China are mainly introduced. Based on the development experience of manned submersibles named "Jiaolong" and "Deep-sea Warrior", the deep-sea manned submersible technology system is formed in China. In the range of 4500-7000 m deep-sea diving, China's manned deep diving technology has been at the international forefront in general, and has independent intellectual property rights. The idea of genealogical development of manned deep diving technology towards the whole ocean depth and the whole sea area has become clear. In the next 15 years, China should focus on consolidating and improving the operation ability, actively expanding the application field, constantly improving the level of intelligence, lightweight, heavy load, and cluster coordination, and carefully building the industrial chain, thus to become a powerful country in manned deep diving technology.
\end{abstract}

Keywords: submersible; manned; deep sea; key technology; genealogical development

收稿日期 : 2019-06-22; 修回日期 : 2019-11-13

通讯作者: 胡震, 中国船舶科学研究中心研究员, 主要研究方向为深海潜水器总体设计与控制、水下机器人视觉感知与操控; E-mail: 7000m@vip.sina.cn

资助项目：中国工程院咨询项目“海洋强国战略研究 2035” (2018-ZD-08)

本刊网址：www.engineering.org.cn/ch/journal/sscae 


\section{一、前言}

21 世纪是海洋的世纪, 海洋资源的开发与利用 已成为全球竞争的焦点领域：世界各国纷纷加快海 洋油气开发进程, 从浅海逐步走向深海; 海底可燃 冰资源丰富, 开发利用技术获得重大突破; 深海多 金属结核、水下富钴结壳、深海热液硫化物等矿产 资源开辟了战略金属资源储备的新通道。

受战略需求牵引, 海洋强国正在形成从先进水 面支持母船, 到可下潜 1000 11000 m 的载人/无 人深海潜水器, 以及探测、作业技术与装备的综合 谱系。人在现场的直接面对、感受、分析、判断和 操作, 始终是认知复杂海洋, 尤其是未知深海最为 有效的方式。

载人潜水器作为一种深海运载工具, 可将科 学技术人员与工程技术人员、各种电子装置与机械 设备等快速、精确地运载到目标海底环境中, 遂行 高效勘探测量和科学考察任务, 已经成为人类开展 深海研究、开发和保护的重要技术手段和装备。载 人潜水器与搭载人员配合, 可以有效地收集信息、 详细地描述周围环境、快速地在现场做出正确的 反应。过去的 50 年中, 载人潜水器的安全运行、 关键技术的逐渐完善, 支撑并推动了深海探测领
域的重大进步 [1]。

本文从国内外载人深潜装备与技术发展历程、 发展现状的角度进行了系统梳理, 重点阐述我国载 人潜水器的应用情况及技术成就。以 “蛟龙” 号和 “深海勇士”号的研制与应用为例, 凝练我国载人 深潜关键技术体系, 分析未来装备与技术发展趋势。

\section{二、国外发展现状}

\section{（一）载人潜水器产业}

在强劲市场需求和先进技术进展的共同推动下, 载人潜水器产业发展势头强劲（见表 1)。2018 年, 海洋技术协会载人潜水器委员会的研究数据表明 [2], 全球载人潜水器活跃数量为 160 艘, 可提供 1624 个 载人座位; 其中 38 艘应用于援潜救生, 122 艘应用 于科学研究、商业作业、观光旅游等。

载人潜水器产业包括制造商、运营者、研究船、 行业协会等。 2000 年以来, 新成立了以载人潜水器 设计、制造和运营为主业的众多商业公司。截至目 前, 载人潜水器保持着良好的安全记录, 这和船级 社在安全设计和建造认证等方面的努力密不可分, 例如, 经由第三方船级社进行认证的载人潜水器比 例高达 92\%。

表 1 现役载人潜水器（工作深度 $>1000 \mathrm{~m}$ )

\begin{tabular}{lcccc}
\hline 名称 & 运营机构 & 深度/m & 载员 / 人 & 建成时间 / 年 \\
\hline $\begin{array}{l}\text { Deepsea Challenger } \\
\text { “蛟龙” 号 }\end{array}$ & 美国伍兹霍尔海洋研究所 (WHOI) & 11000 & 1 & 2011 \\
Shinkai 6500 & 中国大洋协会 (COMRA) & 7000 & 3 & 2009 \\
Mir1 & 日本海洋研究开发机构 (JAMSTEC) & 6500 & 3 & 1989 \\
Mir2 & 俄罗斯科学院 (RAS) & 6000 & 3 & 1987 \\
Rus & RAS & 6000 & 3 & 1987 \\
Consul & 俄罗斯海军 & 6000 & 3 & 2001 \\
Nautile & 俄罗斯海军 & 6000 & 3 & 2011 \\
New Alvin & WHOI & 6000 & 3 & 1985 \\
“深海勇士” 号 & 法国海洋开发研究院（IFREMER） & 4500 & 3 & 2013 \\
PISCES IV & 中国科学院 & 4500 & 3 & 2017 \\
PISCES V & HURL & 2000 & 3 & 1971 \\
TRITON 3000 & 美国夏威夷水下研究实验室 (HURL) & 2000 & 3 & 1973 \\
Deep Rover & HURL & 1000 & 3 & 2011 \\
Deep Rover DR2 & 美国阿卢西亚号科考船 & 1000 & 1 & 1984 \\
LULA 1000 & 加拿大潜水公司 & 1000 & 2 & 1994 \\
\hline
\end{tabular}




\section{（二）深海载人潜水器}

\section{1. 发展历程}

1960 年 1 月，瑞士人皮卡德父子乘坐 “的里雅 斯特” 号载人深潜器, 到达了太平洋的马里亚纳 海沟 (深度 $10913 \mathrm{~m}$ ), 自此拉开了向深海进军 的序幕。彼时虽然人类已经能到达海洋的绝大部 分深度, 但这距离认识深海、利用深海尚有较大 距离。

随着计算机、材料、水声、图像等技术的发展, 以法国、苏联/俄罗斯、日本、美国为代表, 海洋 大国从 20 世纪 80 年代起, 完成了多艘 $6000 \mathrm{~m}$ 级 深海载人潜水器的研制 (见图 1) [3 6]。这些运载 器的应用, 充分显示了专业人员亲临深海和洋底现 场进行直接观察和勘查的优越性, 到达范围遍及大 陆坡、2000 4000 m 深度的海山、火山口、洋脊以 及 $6000 \mathrm{~m}$ 深度的洋底, 获得了大量的地质、沉积 物、生物、地球化学和地球物理的重要发现。

2000 年以来, 有关深海载人潜水器的研究重 新活跃起来, 特别是全海深 (11000 米级) 载人 潜水器的研制, 引发了新一轮行业技术发展 [7]。 2012 年 3 月, 美国卡梅隆团队研制的载人潜水器 Deepsea Challenger 号创造了单人下潜的深度记录 $(10898 \mathrm{~m})$ 。尽管不是一艘作业型的载人潜水器,
但一些技术特点准确契合了载人潜水器技术的发展 趋势, 如: 载人舱大内径 $(1.1 \mathrm{~m})$ 、以高强度钢作 为建造材料、潜浮速度大 $(150 \mathrm{~m} / \mathrm{min})$ 、新型照明 布局（LED 光源, 最长 $2.4 \mathrm{~m}$ ）等。

\section{2. 发展现状}

\section{(1) 升级改造}

美国 “阿尔文”号载人潜水器自 1964 年交付 以来完成了多次大修，2013 年启动了最全面的升级 改造（见图 2), 包括：全新的载人球内径更大, 潜 深可达 $6500 \mathrm{~m}$; 先进的数字指挥与控制、推进、高 清照像/视频成像、数字科学仪器交互等子系统; 全新的科学工作空间和机械手配置。

\section{（2）全新研制}

针对印度洋 1000 5500 m 深处矿产资源的探测 需求, 印度国家海洋技术研究所研发了深海载人潜 水器, 工作深度为 $6000 \mathrm{~m}$, 具有大于 $30 \mathrm{~m} / \mathrm{min}$ 的 上升和下降速度, $3 \mathrm{~h}$ 到达工作深度。潜水器采用 传统结构设计, 总质量小于 $20 \mathrm{t}$, 钛合金载人球舱 直径为 $2.1 \mathrm{~m}$, 可搭载 3 人, 标准 / 紧急生命支持时 间分别为 $12 \mathrm{~h}$ 和 $72 \mathrm{~h}$ 。

\section{（3）商业观光型}

国外商业公司的观光与探险型载人潜水器发展 也独具特色。尽管潜深指标一般, 但在材料、总体

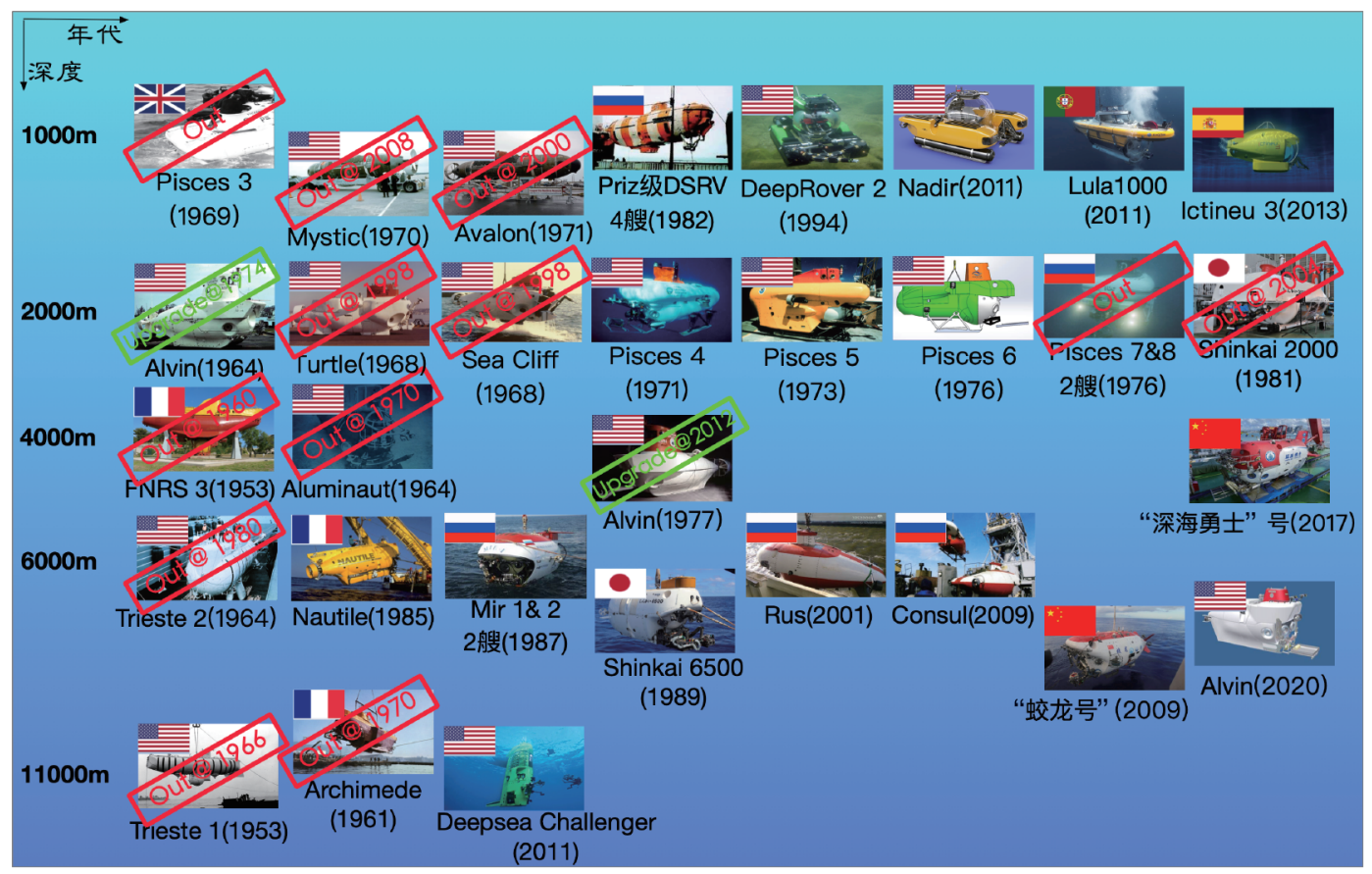

图 1 世界主要深海载人潜水器的发展历程 


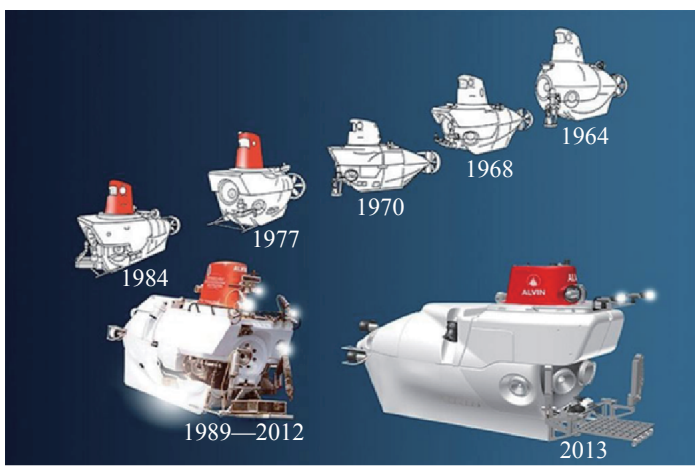

图 2 美国 “阿尔文” 号升级改造历程

结构、动力、操纵性能、布放回收、生命支持与应 急自救等方面都有新的突破, 为深海载人潜水器发 展提供了样板。

1995 年, 美国 SEAmagine 公司研制的商业型 潜水器, 可搭载 2 6 人, 深度级别为 $150 \sim 1500 \mathrm{~m}$ 。 2005 年起, 荷兰 U-Boat Worx 公司发展了系列产品: 2 人型号深度级别为 $3000 \mathrm{~m} 、 3$ 人型号深度级别 为 $2500 \mathrm{~m} 、 5 \sim 11$ 人型号深度级别为 $200 \sim 1700 \mathrm{~m}$ 。 2008 年以来, 美国的 Triton 公司发展了覆盖全海 深范围、搭载 1 7 人的多类潜水器。此外, 加拿 大和俄罗斯等国均有各自的小型观察型载人潜水 器, 已投入市场应用。

(4) 新技术发展型

2018 年, 美国 OceanGate 公司完成了 Titan 载 人潜水器的建造, 可搭载 5 人潜入 $4000 \mathrm{~m}$ 水深, 用于深海的商业探索和研究冒险。Titan 载人潜水 器主要分为两部分: 可搭载 5 人的潜水器本体, 集 成式布放回收平台（见图 3)。

Titan 载人潜水器的亮点设计包括: 复合材料 耐压壳体、大型丙烯酸观察窗、集成式布放回收平 台。集成式布放回收平台将用于布放回收载人潜水 器, 同时还可作为运行维护的浮动平台, 运行在偏 远地区实现更简单、低成本的部署。Titan 载人潜 水器采用了新型的实时船体健康监测 (RTM) 系统, 利用部署在压力边界上的 9 个声学传感器和 18 个 应变计, 能够分析潜水器下潜时压力变化对壳体的 作用力并准确评估结构的完整性。

此外, 美国 Triton Submarines 公司和 EYOS 考 察公司牵头开展了万米深度极限探险活动, 建造了 Triton LF 全海深载人潜水器, 选择了较大高宽比的 立扁型方案 (见图 3)。

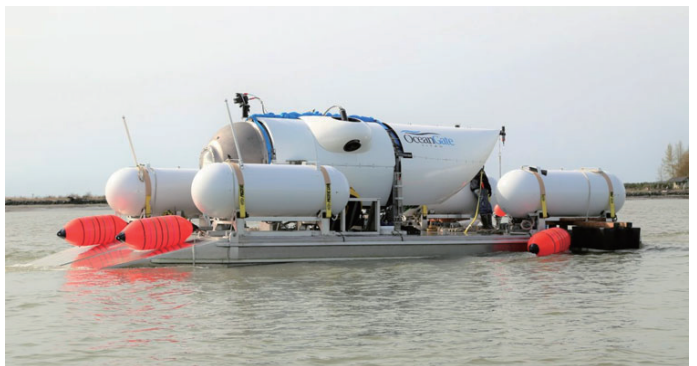

(a) Titan 4000 m载人潜水器

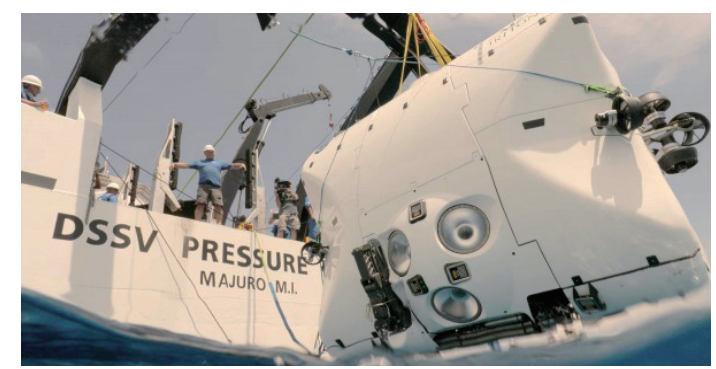

(b) Triton LF万米载人潜水器实物图

图 3 代表性的新技术发展型载人潜水器

\section{三、国内发展情况}

\section{（一）整体情况}

我国在 “八五” 和 “九五” 期间开始了载人潜 水器技术的研究、开发与应用, 集中在援潜救生潜 水器方面, 包括: 200 米级单人常压潜水装具、 600 米级深潜救生艇、200 米级救生钟等。

2000 年以来, 我国载人潜水器领域发展迅速。 2012 年, 研制 7000 米级作业型载人潜水器 “蛟 龙” 号, 在马里亚纳海沟最大下潜深度达 $7062 \mathrm{~m}$ 。 2015 年, 研制 500 米级作业型、仿人形的单人常压 潜水器装具 (ADS); 研制 2 台 “寰岛蛟龙” 型全 通透载客潜水器, 工作深度为 $40 \mathrm{~m}$, 载员 12 人, 商用载客运行获得国家批准试点。2016 年, 启动研 制全海深 (11 $000 \mathrm{~m}$ ) 载人潜水器, 预计 2020 年开 展海上试验。2017 年, 研制 4500 米级作业型载人 潜水器 “深海勇士” 号, 国产化率达 95\%。2018 年, 世界首台大坝深水检测载人潜水器通过中期检查, 工作深度为 $300 \mathrm{~m}$, 即将开始总装联调及示范性应 用。此外, 研制了多型移动型救生钟和机动型救生 钟, 为海军援潜救生提供了国产化装备。

\section{（二）标志性成就}

经过近 20 年的跨越式发展, 我国在载人潜水 
器领域已经建成了完整的技术链条和应用体系, 形 成了三大里程碑。

1. “蛟龙”号载人潜水器创造 $7062 \mathrm{~m}$ 中国载人 深潜记录

2002 年, 国家 863 计划启动了 $7000 \mathrm{~m}$ 载人潜 水器 “蛟龙” 号的研制工作 (见图 4 和表 2)。通 过全国近百家优势科研机构的联合攻关，历经方案 设计、加工制造、总装联调、水池功能性试验等 阶段, 于 2008 年初具备了出海试验的技术条件。 2009 年 8-10 月、2010 年 5-7 月、2011 年 78 月和 2012 年 6-7 月, 分别完成了 1000 米级、 3000 米级、5000 米级和 7000 米级海上试验任务, 最大下潜深度达到了 $7062 \mathrm{~m} 。 2013$ 年, $7000 \mathrm{~m}$ 载 人潜水器开始投入应用, 在中国南海、东太平洋锰 结核区、西太平洋富钴结壳区、马里亚纳海沟、西 南印度洋、西北印度洋等海区完成了百余次下潜, 取得了大量生物、矿物、沉积物、岩石等样品, 拍 摄了高清晰海底影像资料, 为开展深海资源和环境 评价提供了重要依据 [8]。2019年, 完成大修与技 术升级后的第一个测试下潜。

2. “深海勇士” 号载人潜水器实现 $4500 \mathrm{~m}$ 深度 的高频次应用

2017 年，国产化达到 95\% 的 “深海勇士” 号 载人潜水器完成了研制和海试, 成功交付用户 (见 图 5 和表 3)。该潜水器最大作业深度为 $4500 \mathrm{~m}$, 广泛采用国产化技术, 包括载人舱、浮力材料、定 位声呐、推力器、液压源、机械手、充油锂电池组、 超高压海水泵、水下照明、声学设备等, 重点提升 了实用性、经济性和可维护性。

2018 年，“深海勇士”号投入实际应用，在中 国南海、西南印度洋累计下潜超过 100 次, 承担了 科学调查、海洋考古、水下打捞、热液考察等深海

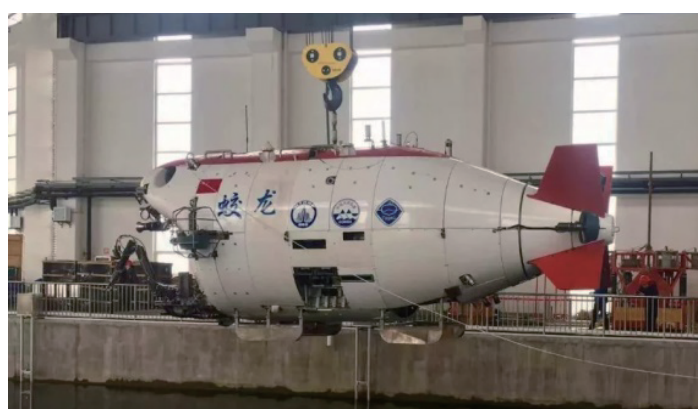

图 4 “蛟龙” 号大修与技术升级
作业任务, 取得丰硕科研成果。在实际应用中，多 次实现夜间下潜、一日两潜, 下潜间隔最短 $5 \mathrm{~h}$, 可与 6000 米级遥控潜水器 (ROV) 联手作业, 展 示了良好的实际应用性能和可靠性 [9]。

3. 全海深载人潜水器目标工作深度为 $11000 \mathrm{~m}$ 2016 年，在国家重点研发计划支持下，组建 了以中国船舶重工集团公司第 702 研究所为总体 集成单位的 “全海深载人潜水器项目群”, 标志着 中国全海深载人潜水器工程研制进入实施阶段, 计划于 2020 年实现万米下潜。2017 年全海深载人 潜水器方案设计通过评审, 目前正处于关键技术 攻关、大型地面试验、样件试制等阶段。该潜水 器同样广泛采用国产化技术, 包括载人舱、浮力 材料、定位声呐、推力器、液压源、机械手、蓄 电池等。2 018 年 12 月, 完成钛合金载人舱球壳焊 接, 焊接一次成型。载人舱是潜水器最核心的主 体构件, 由我国自主研发制造, 此次采用具有国

表 2 “蛟龙” 号载人潜水器基本参数

\begin{tabular}{lc}
\hline 名称 & 参数 \\
\hline 载人数 & 3 人 $(1$ 位驾驶员 +2 位乘客 $)$ \\
尺寸 & $8.3 \mathrm{~m} \times 3.8 \mathrm{~m} \times 3.0 \mathrm{~m}$ \\
载体质量 & $22000 \mathrm{~kg}$ \\
深度 & $7000 \mathrm{~m}$ \\
航速 & $2.5 \mathrm{n} \mathrm{mile/h}$ \\
有效载荷 & $220 \mathrm{~kg}$ \\
推进 & 7 个电动推进器 \\
壳体 & 厚度 $78 \mathrm{~mm}$ 钛合金 \\
生命支持 & 标准 $12 \mathrm{~h} \mathrm{(3)})$ \\
& 紧急 $72 \mathrm{~h}(3$ 人) \\
上浮 $/$ 下潜速度 & $40 \mathrm{~m} / \mathrm{min}$ \\
\hline
\end{tabular}

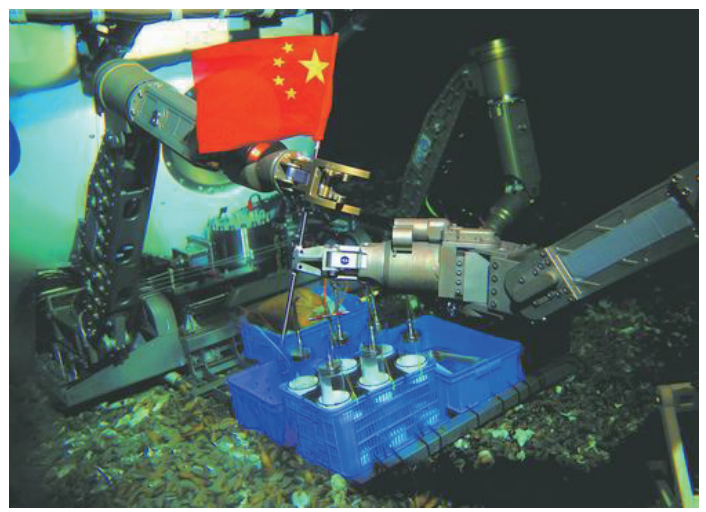

图 5 “深海勇士”号与 ROV 联合作业 
表 3 “深海勇士” 号载人潜水器基本参数

\begin{tabular}{lc}
\hline 名称 & 参数 \\
\hline 载人数 & 3 人 $(1$ 位驾驶员 +2 位乘客 $)$ \\
尺寸 & $8.0 \mathrm{~m} \times 3.0 \mathrm{~m} \times 3.5 \mathrm{~m}$ \\
载体质量 & $20000 \mathrm{~kg}$ \\
深度 & $4500 \mathrm{~m}$ \\
航速 & $2.5 \mathrm{kn}$ \\
有效载荷 & $220 \mathrm{~kg}$ \\
推进 & 6 个电动推进器 \\
壳体 & 厚度 $53 \mathrm{~mm}$ 钛合金 \\
生命支持 & 标准 $10 \mathrm{~h}(3$ 人) \\
& 紧急 $72 \mathrm{~h}(3$ 人 $)$ \\
上浮 $/$ 下潜速度 & $50 \mathrm{~m} / \mathrm{min}$ \\
\hline
\end{tabular}

际先进水平的真空电子束焊接方法, 使焊接精度大 幅提高。

\section{四、关键技术及发展趋势}

\section{（一）我国载人潜水器技术现状分析}

载人潜水器对深海技术与装备具有全面的带动 作用。经过长期技术积累与重点任务攻关, 特别是 “蛟龙” 号和 “深海勇士” 号载人潜水器的成功研制 与应用, 我国载人深潜技术总体上已处于国际前列。

在两型载人潜水器的研制过程中, 突破的关键 技术有 $[10,11]$ : 大深度载人潜水器总体优化设计与 集成、复杂线型水下航行体水动力性能预报与优化、 功能模块化/结构分块化总体布置设计、运载器无 动力下潜 / 上浮、大深度载人钛合金球壳设计及制 造、高能量密度深海动力能源、针对作业目标的稳 定悬停定位、以人为中心的信息与自动化系统、高 速水声通信和高分辨率测深侧扫声纳、大深度载人 潜水器应急安全与生命支持、轻小型化水下电机、 深海高压海水洜和阀、复杂线型耐海水高压复合材 料轻外壳的设计与制造等。

充分发挥社会主义市场经济条件下科技创新的 新型举国体制优势, 组织国内优势技术单位进行联 合攻关，突破了 “载人深潜” 关键技术体系，辐射 带动了深海装备领域的技术发展。例如, 通过 “蛟 龙” 号的研制, 带动了我国以下技术的大幅度提升: (1)材料领域中的高强度钛合金厚板制造、钛合金焊 接工艺、基于玻璃微珠的浮力材料制造与加工、高 强度复合材料等; (2)电子领域中的深海充油银锌蓄
电池、水密电缆和接插件、深海高性能电机等; (3) 深海方向的推进器、液压、水压、通信、潜水器控 制等。

\section{（二）核心关键技术梳理}

（1）载人潜水器优化设计、安全性评估及应用 技术, 具体包括: 载人潜水器型线、总体布局、载 人舱布局、功能特性等的优化设计技术, 载人潜水 器服役期间各种设备的安全性、可靠性设计与评估 技术, 载人舱内人因工程设计评估技术, 载人潜水 器应用模式及相关体系设计技术等。

（2）载人舱设计、建造及评估技术, 具体包括: 金属及非金属材料载人舱的设计技术，球形、柱形 及其他形状载人舱设计技术, 各种材料及形状的载 人舱建造技术，建造完成后载人舱的检测及其使用 安全性的评估技术等。

(3) 高能量密度动力技术, 具体包括: 充油锂 电池设计、建造及管理技术, 水下燃料电池设计、 建造及管理技术，水下能源安全性评估技术，水下 能源补充技术，新型能源深海应用技术等。

（4）水声技术，具体包括：各种声学设备在潜 水器上的集成设计技术, 船载高速水声通信系统设 计及其装备制造技术等。

（5）导航定位技术，具体包括：高精度、高 可靠性的水声定位技术, 水下复杂环境下连续高 精度导航技术, 水下作业目标搜索及作业点重返 技术等。

（6）浮力材料技术, 具体包括: 大深度低密度 浮力材料的设计、制备、成型技术, 浮力材料的测 试与安全性评估技术等。

（7）载人潜水器安全体系技术, 具体包括: 载 人潜水器技术安全体系设计技术, 潜水器状态检测 与安全性评估技术, 各种抛载机构可靠性设计、评 价技术等。

（8）载人潜水器控制技术, 具体包括: 载人潜 水器在复杂海底环境下的航行控制技术, 可视化的 综合信息显控技术, 载人潜水器控制仿真技术等。

\section{（三）前沿技术趋势判断}

着眼国际前沿, 近年来私营资本的注入, 为海 洋大国新型载人潜水器的研制注入了新的活力。载 人潜水器装备的主要发展方向是全海深载人潜水器 
和专用载人潜水器。可以预判, 未来 15 年将是载 人潜水器装备和技术更新换代的集中时期。

（1）非金属材料载人舱设计建造技术。以美国 OceanGate 公司的 Titan 载人潜水器为例 (见图 6), 技术突破重点是复合材料圆柱形耐压壳体 + 钛合金 材料前后端盖这一新型结构形式, 在承载和减重方 面取得很好的平衡。

（2）全透明材料应用于大视野观察窗的设计、 建造技术。观光型载人潜水器已大量采用全透明材 料应用于大视野观察窗的设计与建造（见图 7), 美 国 SEAmagine 公司 AURORA 系列的工作深度达到 $1000 \mathrm{~m}$ 。

（3）以水动力外形设计技术为主的高速无动力 潜浮技术。美国 DeepFlight 公司的有翼潜水器采用 了 “主动上浮” 设计理念 (见图 8), 利用机翼的水 动力来改变潜水器的水下运动。美国 Triton 公司的 Triton LF 潜水器则采用了高宽比较大的垂直立扁型 设计（见图 3)，仅约 $2.5 \mathrm{~h}$ 即可到达海洋最深处。

(4) 新型高密度耐压蓄电池组技术。西班牙和 美国合作, 开发能在全海深运行的电池模块, 免维 护、循环周期达 4000 次、即插即用。

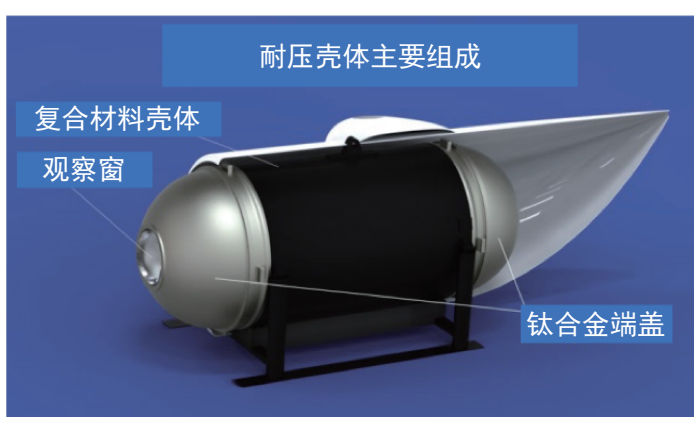

图 6 复合材料耐压壳体

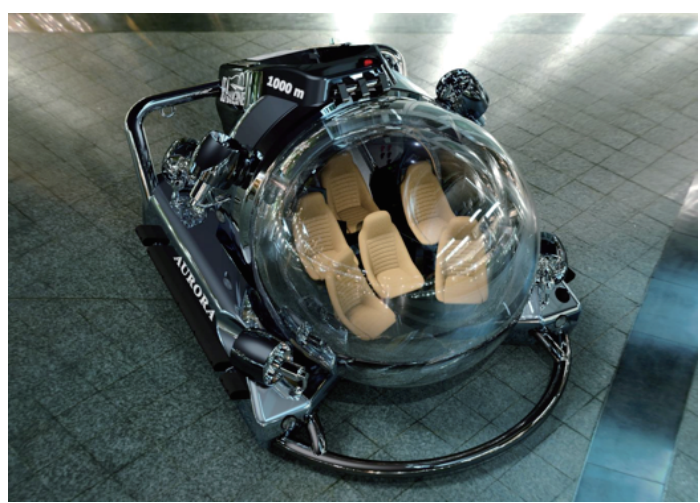

图 7 全透明大视野观察窗

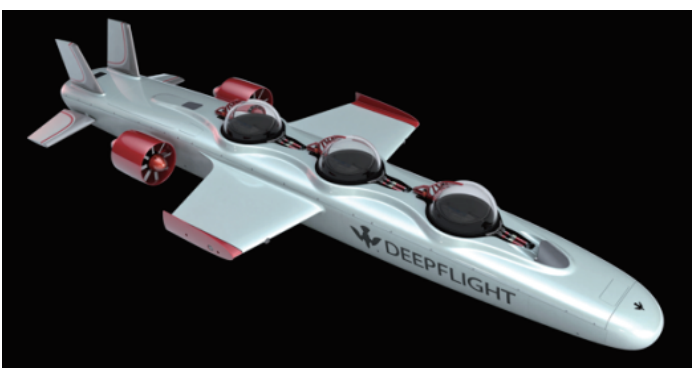

图 8 潜水器新概念外形设计

（5）多人多舱技术。日本提出的全海深载人潜 水器研究计划, 将为 6 名船员提供舒适的乘坐体验 和长达 $48 \mathrm{~h}$ 的任务时间，设置有休息和盃洗空间。

\section{五、结语}

我国载人深潜领域经过近 20 年的跨越式发展, 在 4500 7000 m 深度工作范围，整体上已处于国际 前沿，基本构建了具有自主知识产权的载人深潜关 键技术体系。

未来，我国载人深潜技术向着全海深、全海域 的谱系化发展思路已经逐渐明朗。依托新一代载人 潜水器装备, 有望在 15 年内, 巩固并提升全海深、 江河水库、油气矿产、热液冷泉的作业能力, 有效 拓展搜索、打捞、考古、观光、极地、核能等新应 用领域。同时，不断革新载人潜水器的智能化、轻 量化、重载化和集群协同水平，培育打造产业链条， 支撑海洋强国建设。

\section{参考文献}

[1] 朱大奇, 胡震. 深海潜水器研究现状与展望 [J]. 安徽师范大学 学报 (自然科学版), 2018, 41(3): 205-216.

Zhu D Q, Hu Z. Research status and prospect of deep-sea underwater vehicle $[\mathrm{J}]$. Journal of Anhui Normal University (Natural Science), 2018, 41(3): 205-216.

[2] William K. MTS manned underwater vehicles 2017-2018 global industry overview [J]. Marine Technology Society Journal, 2018, 52(5): 125-151.

[3] 任玉刚, 刘保华, 丁忠军, 等. 载人潜水器发展现状及趋势 [J]. 海 洋技术学报, 2018, 37(2): 114-121.

Ren Y G, Liu B H, Ding Z J, et al. Research on the current status and development trend of manned submersibles [J]. Journal of Ocean Technology, 2018, 37(2): 114-121.

[4] 赵羿羽. 世界主要载人潜水器下潜活动概述 [J]. 船舶物资与市 场, 2018, 149(1): 41-48.

Zhao Y Y. Overview of diving activities of major manned submersible vehicles in the world [J]. Marine Equipment / 
Materials \& Marketing, 2018, 149(1): 41-48.

[5] Anatoly M S. 30 years experience of Mir submersibles for the ocean operations [J]. Deep Sea Research Part II: Topical Studies in Oceanography, 2018, 155(9): 83-95.

[6] 刘峰. 深海载人潜水器的现状与展望 [J]. 工程研究, 2016, 8(2): 172-178.

Liu F. Technical status and development trend of the deep-sea manned submeisible [J]. Journal of Engineering Studies, 2016, 8(2): 172-178.

[7] 徐伟哲, 张庆勇. 全海深潜水器的技术现状和发展综述 [J]. 中 国造船, 2016, 57(2): 206-221.

Xu W Z, Zhang Q Y. Overview of present status and development trend of full ocean depth submersibles [J]. Shipbuilding of China, 2016, 57(2): 206-221.

[8] 崔维成, 刘峰, 胡震, 等. 蛟龙号载人潜水器的7000米级海上试 验 [J]. 船舶力学, 2012, 16(10): 1131-1143.
Cui W C, Liu F, Hu Z, et al. $7000 \mathrm{~m}$ sea trials test of the deep manned submersible "Jiao Long" [J]. Journal of Ship Mechanics, 2012, 16(10): 1131-1143.

[9] 张同伟, 唐嘉陵, 杨继超, 等. $4500 \mathrm{~m}$ 以深作业型载人潜水器 [J]. 船舶工程, 2017, 39(6): 77-83.

Zhang T W, Tang J L, Yang J C, et al. Deep operational manned submersibles $>4500 \mathrm{~m}$ [J]. Ship Engineering, 2017, 39(6): 77-83.

[10] 刘涛, 王璇, 王否, 等. 深海载人潜水器发展现状及技术进展 [J]. 中国造船, 2012, 53(3): 233-243.

Liu T, Wang X, Wang L, et al. The current status and technical development of deep sea manned submeisible [J]. Shipbuilding of China, 2012, 53(3): 233-243.

[11] 赵翌羽, 曾晓光, 郎舒妍. 深海载人潜水器技术动向 [J].中国船 检, 2016 (11): 94-97.

Zhao Y Y, Zeng X G, Lang S Y. Technical trends of deep-sea manned submersible [J]. China Ship Survey, 2016 (11): 94-97. 